\title{
ESPORULAÇÃO DE Mycosphaerella fijiensis EM DIFERENTES MEIOS DE CULTURA
}

\section{ROGÉRIO E. HANADA ${ }^{1}$, LUADIR GASPAROTTO ${ }^{2}$ \& JOSÉ CLÉRIO R. PEREIRA ${ }^{2}$}

\author{
${ }^{1}$ Instituto Nacional de Pesquisas da Amazônia, Cx. Postal 478, CEP 69011-970, Manaus, AM, \\ e-mail:rhanada@inpa.gov.br; ²Embrapa Amazônia Ocidental, Cx. Postal 319, CEP 69011-970, Manaus, AM
}

(Aceito para publicação em 14/11/2002)

Autor para correspondência: Rogério Eiji Hanada

HANADA, R.E., GASPAROTTO, L. \& PEREIRA, J.C.R. Esporulação de Mycosphaerella fijiensis em diferentes meios de cultura. Fitopatologia Brasileira 27:170-173. 2002.

\section{RESUMO}

Avaliou-se a esporulação de conídios de Mycosphaerella fijiensis (isolado LPM472) em sete meios de cultura (batata dextrose ágar, $\mathrm{V} 8$ ágar, $\mathrm{V} 8 \mathrm{CaCO}_{3}$ ágar, água de coco ágar, batata cenoura ágar, folha de banana ágar e micophil) sob quatro regimes de luminosidade (escuro contínuo, fotoperíodo de $12 \mathrm{~h}$, luz contínua e seqüencial - dez dias no escuro e cinco dias sob luz contínua). O ensaio foi conduzido em delineamento inteiramente casualizado, com cinco repetições. A esporulação foi determinada em erlenmeyer de $125 \mathrm{ml}$, contendo $20 \mathrm{ml}$ de seu respectivo meio de cultura e $0,5 \mathrm{ml}$ de suspensão com $5 \times 10^{4}$ conídios de $M$. fijiensis/ml, mantidos a $25^{\circ} \mathrm{C} \pm 2{ }^{\circ} \mathrm{C}$, durante 15 dias. Não ocorreu esporulação em todos os meios de cultura sob regime de escuro contínuo, assim como no meio de folha de banana ágar, sob todos os regimes de luminosidade. No regime de fotoperíodo, ocorreu esporulação apenas nos meios $\mathrm{V} 8 \mathrm{CaCO}_{3}$ ágar e michophil, e no regime de luz contínua, apenas no micophil. No regime seqüencial, os meios de batata dextrose ágar e $\mathrm{V} 8 \mathrm{CaCO}_{3}$ ágar propiciaram as maiores produções de conídios.

Palavras-chave adicionais: Sigatoka negra, banana, regime de luminosidade, Musa spp.

\section{ABSTRACT \\ Sporulation of Mycosphaerella fijiensis in different culture media}

The conidial production of Mycosphaerella fijiensis (isolate LPM472) was evaluated on seven culture media (potato dextrose agar, V8 agar, V8 $\mathrm{CaCO}_{3}$ agar, coconut water agar, potato carrot agar, banana leaf extract agar and mycophil) under four different light exposure regimes (continuous darkness, 12-hour photoperiod, continuous light and ten days under continuous darkness followed by five days of continuous light). The experiment was arranged using a completely random factorial design with five replications with factor A being the four light regimes and factor $B$ being the seven types of media. An erlenmeyer flask $(125 \mathrm{ml})$ containing $20 \mathrm{ml}$ of culture media and
$0,5 \mathrm{ml}$ of conidial suspension $\left(5 \times 10^{4}\right.$ conidia/ml $)$ was considered as an experimental unit incubated at $25{ }^{\circ} \mathrm{C} \pm 2{ }^{\circ} \mathrm{C}$ for 15 days. Sporulation was quantified by counting the number of conidia in a Neubaeur chamber. No sporulation was observed under continuous darkness or for the banana leaf extract agar. Under the 12-hour- photoperiod regime, only mycophil and $\mathrm{V} 8 \mathrm{CaCO}_{3}$ agar provided sporulation while under continuous light, leave in mycophil resulted in sporulation. The best conidial production was obtained on PDA and $\mathrm{V} 8 \mathrm{CaCO}_{3}$ agar under the ten days of continuous darkness followed by five days of continuous light regime.

\section{INTRODUÇÃO}

A Sigatoka negra da bananeira (Musa spp.), causada pelo fungo Mycosphaerella fijiensis Morelet, estádio anamórfico Paracercospora fijiensis (Morelet) Deighton, é considerada a doença mais destrutiva da bananeira (Pons, 1987; Stover \& Simmonds, 1987). No Brasil, foi constatada em 1998 (Pereira et al., 1998) e atualmente encontra-se disseminada nos estados de Roraima, Rondônia, Acre, Amazonas, Mato Grosso, Amapá e Pará. Nas regiões onde a doença ocorre, os danos atingem 100\% da produção (Pereira et al., 1998).

Apesar da importância do patógeno, existem poucas publicações sobre a epidemiologia e biologia de $M$. fijiensis, sendo a maioria derivada principalmente de observações de campo (Jacome \& Schuh, 1993a). Assim, pouco se conhece dos efeitos das condições climáticas, variações genéticas do patógeno e tipo de resistência do hospedeiro. Para desenvolver estudos dessa natureza, há necessidade de se fazer inoculações artificiais em ambientes controlados, o que requer a produção massal de esporos do patógeno.

A composição do meio de cultura determina a quantidade e qualidade do crescimento micelial e esporulação dos fitopatógenos (Dhingra \& Sinclair, 1995). Entretanto, espécies de Cercospora, geralmente apresentam baixa esporulação ou não esporulam em meio de cultura artificial (Nagel, 1934). Mourichon et al. (1987) conseguiram esporulação de $M$. fijiensis em meio $\mathrm{V} 8 \mathrm{CaCO}_{3}$ ágar, e Jacome et al. (1991), Jacome \& Schuh (1993b) e Romero \& Sutton (1997) em meio micophil ágar (MA). Além desses, Gonzáles (1999) cita os 
meios batata dextrose ágar (BDA) e V8 ágar como propícios à esporulação do patógeno.

Além do meio de cultura, a temperatura e a luminosidade são fatores essenciais para estimular a esporulação dos fitopatógenos (Dhingra \& Sinclair, 1995). Jacome \& Schuh (1993b) verificaram que $M$. fijiensis cresce numa faixa de 20 a $30{ }^{\circ} \mathrm{C}$, esporulando após 14 a 18 dias, em meio de MA, sob luz contínua.

Neste trabalho, avaliaram-se os efeitos de meios de cultura e regimes de luminosidade na esporulação de conídios de $M$. fijiensis.

\section{MATERIAL E MÉTODOS}

O trabalho foi realizado nos laboratórios de Fitopatologia da Embrapa Amazônia Ocidental e Patologia de Madeira (LPM) do Instituto Nacional de Pesquisas da Amazônia, em Manaus, AM.

Utilizou-se o isolado LPM472 de M. fijiensis obtido de folhas de bananeiras da cultivar Prata Anã, apresentado sintomas da doença, proveniente da área experimental da Embrapa Amazônia Ocidental. Pelo método direto, transferiram-se estruturas reprodutivas do patógeno para placas de Petri contendo meio de BDA e cloranfenicol 250 ppm.

Culturas de $M$. fijiensis, crescidas em placa de Petri contendo meio de BDA, com 15 dias de incubação a $25^{\circ} \mathrm{C} \pm$ $2{ }^{\circ} \mathrm{C}$ no escuro, foram utilizadas para multiplicação de inóculo. Em um béquer de $50 \mathrm{ml}$, triturou-se o micélio de $M$. fijiensis em $5 \mathrm{ml}$ de água destilada esterilizada e distribuiu-se proporcionalmente em quatro erlenmeyers de $250 \mathrm{ml}$ contendo meio $\mathrm{V} 8 \mathrm{CaCO}_{3}$ ágar e antibiótico cloranfenicol $250 \mathrm{ppm}$, os quais foram mantidos em incubadora, por 15 dias, a $25^{\circ} \mathrm{C}$ $\pm 2{ }^{\circ} \mathrm{C}$ sob regime de luz sequiencial. Em seguida, preparouse uma suspensão de 5.000 conídios/ml. Da suspensão, uma alíquota de $0,5 \mathrm{ml}$ foi colocada em cada erlenmeyer de 125 $\mathrm{ml}$ contendo $20 \mathrm{ml}$ de seus respectivos meios de cultura. Todos erlenmeyers foram mantidos em incubadora, durante 15 dias, a $25^{\circ} \mathrm{C} \pm 2{ }^{\circ} \mathrm{C}$ sob seus respectivos regimes de luminosidade.

Os meios de cultura testados foram: V8 ágar [100 ml de V8 (Campbell Soup Company), $20 \mathrm{~g}$ de ágar e $900 \mathrm{ml}$ de água destilada), $\mathrm{V} 8 \mathrm{CaCO}_{3}$ ágar ( $100 \mathrm{ml}$ de V8, 2 g de $\mathrm{CaCO}_{3}$, $20 \mathrm{~g}$ de ágar e $900 \mathrm{ml}$ de água destilada], BCA (extrato de 20 $\mathrm{g}$ de batata e $20 \mathrm{~g}$ de cenoura, $20 \mathrm{~g}$ de ágar e água destilada, quantidade suficiente para $1.000 \mathrm{ml}), \mathrm{ACA}(1.000 \mathrm{ml}$ de água de coco e $20 \mathrm{~g}$ de ágar), BDA (extrato de $200 \mathrm{~g}$ de batata, 20 $\mathrm{g}$ de dextrose, $20 \mathrm{~g}$ de ágar e água destilada, quantidade suficiente para $1.000 \mathrm{ml}$ ), FBA (extrato de $300 \mathrm{~g}$ de folhas de banana triturada com auxílio de mix, decocto por $2 \mathrm{~h}$ e filtrada, $20 \mathrm{~g}$ de ágar e água destilada, quantidade suficiente para 1.000 $\mathrm{ml}$ ) e micophil ágar (10 $\mathrm{g}$ de farinha de soja, $10 \mathrm{~g}$ de dextrose, $20 \mathrm{~g}$ de ágar e $1.000 \mathrm{ml}$ de água destilada). Os quatro regimes de luminosidade empregados foram: escuro contínuo, luz contínua, fotoperíodo de $12 \mathrm{~h}$ de luz e seqüencial (dez primeiros dias no escuro e cinco dias subseqüentes sob luz contínua). As unidades experimentais do regime escuro contínuo foram colocadas em uma caixa de papelão com tampa e as de luz contínua foram dispostas em prateleiras sob duas lâmpadas fluorescentes de $40 \mathrm{~W}$ posicionadas a uma distância aproximada de $40 \mathrm{~cm}$. O ensaio foi conduzido em delineamento inteiramente casualizado com cinco repetições por tratamento.

Determinou-se o número de conídios, adicionando-se $3 \mathrm{ml}$ de água destilada em cada erlenmeyer, removendo-se os esporos com um pincel. Da suspensão obtida, quantificou-se a esporulação de conídios por meio de quatro leituras em câmara de Neubaeur. Os dados obtidos foram transformados para ln (esporulação +1) e analisados no SAS System.

Após definir os meios de cultura e o regime de luz mais adequado para esporulação do isolado LPM472 de $M$. fijiensis, avaliou-se a efetividade do meio de BDA sob o regime de luz seqüencial na esporulação de conídios de outros isolados. Testaram-se 11 isolados de diferentes procedências geográficas: LPM475 cv. Maçã - Cárceres, MT; LPM479 cv. Nanicão - Manaus, AM; LPM480 cv. Pioneira - Manaus, AM; LPM501 cv. Mysore - São Gabriel da Cachoeira, AM; LPM 502 cv. Maçã - São Gabriel da Cachoeira, AM; LPM503 cv. Prata - São Gabriel da Cachoeira, AM; LPM504 cv. Nanicão - São Gabriel da Cachoeira, AM; LPM526 cv. PAO322 - Iranduba, AM; LPM 527 cv. Nanicão - Iranduba ,AM; LPM 529 cv. Prata Anã - Rio Preto da Eva, AM; LPM 531 cv. SH3640 - Rio Preto da Eva, AM. O isolado LPM472 cv. Prata Anã - Manaus, AM, utilizado no ensaio anterior, serviu como padrão para este ensaio. Os procedimentos empregados foram semelhantes aos utilizados no ensaio anterior. $\mathrm{O}$ delineamento experimental foi inteiramente casualizado com cinco repetições por tratamento.

\section{RESULTADOS E DISCUSSÃO}

De acordo com os resultados do efeito dos meios de cultura, submetidos a quatro regimes de luminosidade, $M$. fijiensis (Tabela 1) apresentou maior esporulação nos meios de $\mathrm{BDA}$ e $\mathrm{V} 8 \mathrm{CaCO}_{3}$ ágar quando submetido ao regime de luz seqüencial; sob regime de fotoperíodo de $12 \mathrm{~h}$, ocorreu esporulação somente no $\mathrm{V} 8 \mathrm{CaCO}_{3}$ ágar e MA, sendo superior no V8 $\mathrm{CaCO}_{3}$ ágar (Tabela 1). Sob luz contínua, esporulou apenas em meio de MA e sob escuro contínuo, não esporulou em nenhum dos meios de cultura testados (Tabela 1).

O meio de FBA não estimulou a esporulação de $M$. fijiensis nos regimes de luminosidade testados. Por outro lado, os meios mais ricos propiciaram maior esporulação, contrapondo-se a Dhingra \& Sinclair (1995) que recomendam meios mais pobres para estimular a esporulação de fungos. Tuite (1969) e Satyanarayana \& Sadasiva Reddy (1986) recomendam que meios preparados a partir de partes de plantas suscetíveis podem aumentar as chances de esporulação, porém, o decocto de folha de bananeira não estimulou a esporulação de $M$. fijiensis.

Uma das características de M. fijiensis é o crescimento micelial lento. Somente a partir do quinto dia de incubação observou-se o início do desenvolvimento das colônias, e com nove a dez dias toda a superfície do meio de cultura foi tomada 
R.E. Hanada et al.

TABELA 1 - Produção de conídios de Mycosphaerella fijiensis em meios de cultura sob quatro regimes de luminosidade: escuro contínuo (EC); fotoperíodo 12 h (FP); seqüencial - dez dias no escuro e cinco dias subseqüente sob luz contínua (SEQ); luz contínua (LC)

\begin{tabular}{|c|c|c|c|c|c|c|c|c|}
\hline \multirow{3}{*}{$\begin{array}{l}\text { Meio de } \\
\text { Cultura }^{1}\end{array}$} & \multicolumn{8}{|c|}{ Regimes de Luminosidade $^{2}$} \\
\hline & \multicolumn{2}{|c|}{ EC } & \multicolumn{2}{|c|}{ FP } & \multicolumn{2}{|c|}{ SEQ } & \multicolumn{2}{|c|}{$\mathbf{L C}$} \\
\hline & $\mathbf{A}$ & B & $\mathbf{A}$ & B & $\mathbf{A}$ & B & $\mathbf{A}$ & B \\
\hline V8 & $0,00 \mathrm{Ab}$ & & $0,00 \mathrm{Cb}$ & 0,00 & $14,36 \mathrm{Ba}$ & 17,54 & $0,00 \mathrm{Bb}$ & 0,00 \\
\hline $\mathrm{V} 8 \mathrm{CaCO}_{3}$ & $0,00 \mathrm{Ac}$ & 0,00 & $13,28 \mathrm{Ab}$ & 5,97 & $14,96 \mathrm{Aa}$ & 31,51 & $0,00 \mathrm{Bc}$ & 0,00 \\
\hline $\mathrm{BCA}$ & $0,00 \mathrm{Ab}$ & 0,00 & $0,00 \mathrm{Cb}$ & 0,00 & $10,63 \mathrm{Da}$ & 0,43 & $0,00 \mathrm{Bb}$ & 0,00 \\
\hline ACA & $0,00 \mathrm{Ab}$ & 0,00 & $0,00 \mathrm{Cb}$ & 0,00 & $14,53 \mathrm{Ba}$ & 0,78 & $0,00 \mathrm{Bb}$ & 0,00 \\
\hline BDA & $0,00 \mathrm{Ab}$ & 0,00 & $0,00 \mathrm{Cb}$ & 0,00 & $15,09 \mathrm{Aa}$ & 6,17 & $0,00 \mathrm{Bb}$ & 0,00 \\
\hline FBA & $0,00 \mathrm{Aa}$ & 0,00 & $0,00 \mathrm{Ca}$ & 0,00 & $0,00 \mathrm{Ea}$ & 0,00 & $0,00 \mathrm{Ba}$ & 0,00 \\
\hline MA & $0,00 \mathrm{Ac}$ & 0,00 & $10,35 \mathrm{Bb}$ & 0,32 & $11,01 \mathrm{Ca}$ & 0,61 & $10,60 \mathrm{Ab}$ & 0,41 \\
\hline
\end{tabular}

${ }^{1} \mathrm{~V} 8$ = V8 ágar; $\mathrm{V} 8 \mathrm{CaCO}_{3}=\mathrm{V} 8 \mathrm{CaCO}_{3}$ ágar; $\mathrm{BCA}=$ batata cenoura ágar; $\mathrm{ACA}=$ água de coco ágar; $\mathrm{BDA}=$ batata dextrose ágar; $\mathrm{FBA}=$ folha de bananeira ágar; $\mathrm{MA}=$ micophil agar.

${ }^{2}$ A - Dados transformados para ln $(\mathrm{x}+1)$, onde x é a esporulação de $M$. fijiensis. B - Dados originais, produção de conídios de $M$. fijiensis/erlenmeyer x $10^{5}$. Médias seguidas pela mesma letra maiúscula na coluna e minúscula na linha não diferem entre si pelo teste Tukey $(\mathrm{P}=0,05)$.

por pequenas colônias. O crescimento micelial de M. fijiensis ocorreu em todos os meios quando submetidos aos regimes de escuro contínuo e de luz seqüencial. Quando submetido ao regime de luz contínua, o crescimento micelial ocorreu apenas no meio de MA. Sob fotoperíodo de $12 \mathrm{~h}$ o micélio cresceu apenas nos meios V8 $\mathrm{CaCO}_{3}$ ágar e MA. Portanto, a luz inibiu o desenvolvimento micelial de $M$. fijiensis em quase todos os meios de cultura, enquanto que o escuro favoreceu o crescimento micelial do fungo.

A luminosidade foi um fator fundamental na esporulação de $M$. fijiensis, uma vez que no regime de escuro contínuo o fungo não esporulou (Tabela 1). Resultados semelhantes foram obtidos por Jacome \& Schuh (1993b). No entanto, nos regimes de fotoperíodo de $12 \mathrm{~h}$, luz seqüencial e luz contínua, alguns meios propiciaram a esporulação de $M$. fijiensis, sendo o regime seqüencial o mais eficiente. Com fotoperíodo de $12 \mathrm{~h}$ o fungo apresentou baixa esporulação nos meios de $\mathrm{MA}$ e $\mathrm{V} 8 \mathrm{CaCO}_{3}$ ágar, corroborando com os relatos de Jacome \& Schuh (1993b). Em luz contínua ocorreu esporulação apenas em meio de MA, confirmando, também, os resultados de Jacome \& Schuh (1993b). No mesmo regime de luminosidade, Mourichon et al. (1987) conseguiram esporulação de $M$. fijiensis em meio de V8 CaCO3 ágar, resultado não observado neste trabalho. Quando se submeteu ao regime de luz seqüencial, com exceção do meio de FBA, nos demais meios ocorreram esporulação. Todavia, é importante ressaltar que a sequiencial está sendo adotada pela primeira vez para estimular a esporulação de $M$. fijiensis. Portanto, M. fijiensis independentemente do meio de cultura, necessita de luminosidade para esporular. Segundo Del Peloso et al. (1989), é provável que a luz possibilite a síntese de compostos essenciais à esporulação, ausentes no meio de cultura.

Os resultados referentes à esporulação dos diferentes isolados, cultivados em meio de BDA e submetidos ao regime de luz seqüencial (Tabela 2) mostraram que apesar da diferença na quantidade de conídios produzidos pelos diferentes isolados, a esporulação de todos isolados foi estatisticamente semelhante à esporulação do isolado LPM472, considerado como padrão, destacando-se LPM502 com a maior esporulação. Estes resultados reforçam a eficiência do meio BDA sob regime de luz seqüencial na esporulação de M. fijiensis.

Diversos trabalhos indicam que isolados de outras espécies de Cercospora podem variar quanto à sua esporulação, quando submetidos a diversas condições de cultivo. Calpouzoz \& Stallknecht (1965) observaram que a esporulação de três isolados de Cercospora beticola Sacc. foi diferente, quando submetidos a diferentes regimes de luminosidade e temperatura. Resultados semelhantes foram

TABELA 2 - Produção de conídios de diferentes isolados de Mycosphaerella fijiensis, em meio de BDA sub o regime de luz seqüencial

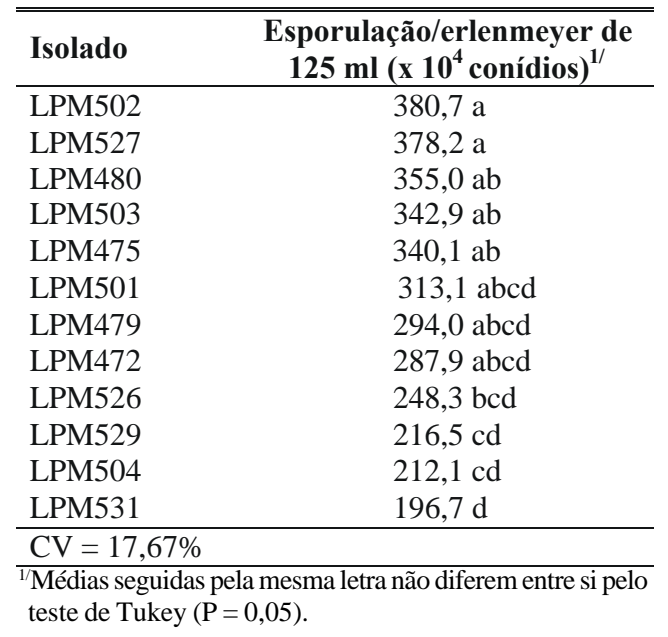


obtidos por Veiga \& Kimati (1974), estudando vários isolados de $C$. sojina Hara em diferentes meios de cultura. El Gholl et al. (1982) observaram que dos 40 isolados monoconidiais de C. kikuchii (Matsumoto \& Tomayasu) Gardner avaliados, $83 \%$ produziram colônias radiais enrugadas e $17 \%$ colônias radiais lisas. A esporulação média por colônias lisas e enrugadas, após oito dias em meio de V8 ágar foi de 35.000 e 96.000 conídios $/ \mathrm{ml}$, respectivamente, demonstrando a variabilidade do patógeno quanto a forma da colônia e esporulação. Asmus \& Dhingra (1983) produziram grande quantidade de conídios de $C$. vanderysti P. Henn. em meios de BDA e suco de folha de cenoura, sob regime de fotoperíodo de 12 h. Fernandes (1989) obteve razoável esporulação de C. coffeicola Berkeley \& Cooke em meio de sucos vegetais Yakult-ágar, após sete dias de incubação. Cordeiro et al. (1999) utilizaram o meio de $\mathrm{V} 8 \mathrm{CaCO}_{3}$ ágar, sob regime de luz contínua, para esporulação de Pseudocercospora musae (Zimmerman) Deighton. Para se obter esporulação de $M$. fijiensis, utilizando os meios $\mathrm{V} 8 \mathrm{CaCO}_{3}$ ágar e BDA como demonstrado neste trabalho, é necessário que se forneça um período de pelo menos dez dias de escuro contínuo, seguido de cinco dias de luz contínua.

\section{REFERÊNCIAS BIBLIOGRÁFICAS}

ASMUS, G.L. \& DHINGRA, O.D. Isolation, cultivation and sporulation of Cercospora vanderysti. Fitopatologia Brasileira 8:305-310. 1983

CALPOUZOZ, L. \& STALLKNECHT, G.F. Sporulation of Cercospora beticola affected by interaction between light and temperature. Phytopathology 55:1370-1371. 1965.

CORDEIRO, Z.J.M., KIMATI, H. \& DIAS, C.T. dos S. Resistência de genótipos de bananeira ao mal-de-sigatoka. Summa Phytopathologica 25:318-323. 1999.

DEL PELOSO, M.C., FERNANDES, C.D., FIGUEIRAS, A.T. \& CHAVES, G.M. Esporulação de Cercospora coffeicola em diferentes meios de cultura. Fitopatologia Brasileira 14:4144. 1989.

DHINGRA, O.D. \& SINCLAIR, J.B. Basic Plant Pathology Methods. Lewis Publishers, Boca Raton, Florida. 1995.

EL GHOLL, N.E, ALFIERI Jr., S.A. Jr., RIDINGS, W.H. \& SCHOULTIES, C.L. Growth and sporulation in vitro of Cercospora apii, Cercospora arachidicola, Cercospora kikuchii, and other species of Cercospora. Canadian Journal of Botany 60:582-688. 1982.

FERNANDES, A.T.F. Componentes que expressam a intensidade da Cercosporiose (Cercospora coffeicola Berk.\& Cook) em progenies de catimor (Tese de Mestrado). Viçosa. Universidade Federal de Viçosa. 1989.

GONZÁLES, M. Metodología para la manipulacíon y cultivo in vitro de Mycosphaerella fijiensis. Manejo Integrado de Plagas 53:i-iv. 1999.

JACOME, L.H., SCHUH, W. \& STEVERSON, R.E. Effect of temperature and relative humidity on germination and germ tube development of Mycosphaerella fijiensis var. difformis. Phytopathology 12:1480-1485. 1991.

JACOME, L.H. \& SCHUH, W. Spore production and artificial inoculation techniques for Mycosphaerella fijiensis var. difformis. Tropical Agriculture 70:33-38. 1993a.

JACOME, L.H. \& SCHUH, W. Effect of temperature on growth and conidial production in vitro, and comparison of infection and aggressiveness in vivo among isolates Mycosphaerella fijiensis var. difformis. Tropical Agriculture 70:51-58. 1993b.

MOURICHON, X., PETER, D. \& ZAPATER, M. Inoculation expérimentale de Mycosphaerella fijiensis Morelet sur de jeunes plantules de bananiers issues de culture in vitro. Fruits 4:195-198. 1987.

NAGEL, C.M. Conidial production in species of Cercospora in pure culture. Phytopathology 24:1101-1110. 1934.

PEREIRA, J.C.R., GASPAROTTO, L., COELHO, A.F.S. \& VÉRAS, S.M. Doenças da bananeira no Estado do Amazonas. EMBRAPA-CPAA, Circular Técnica n ${ }^{\circ}$ 10. 1998.

PONS, N. Notes on Mycosphaerella fijiensis var. difformis. Transactions of the British Mycological Society 89:120124.1987.

ROMERO, R.A. \& SUTTON, T.B. Reaction of four Musa of three temperatures to isolates of Mycosphaerella fijiensis from different geographical regions. Plant Disease 10:1139-1142. 1997.

SATYANARAYANA, K. \& SADASIVA REDDY, C. A new and cheap medium supporting the sporulation of Pyricularia oryzae. Cav. Indian Journal Mycological Plant Pathology 16:329. 1986.

STOVER, R.H. \& SIMMONDS, N.W. Banana. 3rd. Edn, Harlow, Essex, Longman Scientific \& Technical, 1987.

TUITE, J. Plant Pathological Methods, Fungi and Bacteria. Burgess Publishing Company, Minneapolis. 1969.

VEIGA, P. \& KIMATI, H. Influência de meios de cultura e regime luminoso na esporulação de Cercospora sojina Hara. Revista do Centro de Ciências Rurais 4:159-64. 1974. 